\title{
Case Studies and the Teaching of Development
}

\author{
Willie Henderson and Emil R. Rado
}

\begin{abstract}
Introduction'
Development studies courses in the UK draw students from a wide variety of countries and cultures. It is hardly surprising, given the interdisciplinary nature of the subject matter and the transcultural dimension to the teaching/learning problem that development studies teachers be concerned with the quality of the learning environment that is generated on such courses. Given the students and subject matter, traditional lecturing and variations on lecturing do not encourage all the kinds of educational experience that a development studies course might wish to achieve. The main deficiency of the lecture is that it does not actively associate the listener in the learning process. The student's role, though requiring a high degree of concentration, is essentially passive. No creative use is made, as a rule, of the simultaneous presence of other learners, who could enrich one anothers learning, by bearing in on the issues from their differing experience.
\end{abstract}

Case study has evolved as an alternative teaching device that obliges the student to apply theory to practice, in a highly participatory way, (often) taking as its 'unit' not the individual student but the group. This paper explores some of the educational and epistemological questions involved in the creation and use of case study material on development studies courses.

\section{The Case Study as a Teaching Method}

This section examines claims made for case study as a teaching method, particularly for use in small groups. ${ }^{2}$ The general argument is that no single case study is likely to facilitate the practice of all the activities that might be desired of students. But the cumulative use of case material, together with discussion in a variety of different types of groups, is likely to be effective though of course there has to be a process of matching needs and objectives, and some thoughtful planning with respect to structure of case material. We leave aside until later a consideration of concrete definitions and examples of case material.

\footnotetext{
1 Thanks go to Chris Davies, Nick Devas, Adrian Leftwich, John Toye and Dudley Seers for generously commenting on an earlier draft. Any errors and faults after all this help are, of course, our own.

${ }^{2}$ For a detailed list of claims see Davies [1976].
}

\section{Case study versus lecturing}

Naturally there are certain advantages that are to be derived from making use of case studies, but these can be clearly outlined only when the case study is compared with some other teaching method such as lecturing, and when some sort of systematic evaluation of the effectiveness of the case study teaching has taken place. Systematic analysis of the effectiveness of case study in meeting the objectives generally set for it has not, as far as we know, been undertaken, although steps are being taken at Herriot-Watt University to test its effectiveness under controlled conditions for the teaching of economics. ${ }^{3}$

Evidence available on teaching techniques suggests that lectures are an effective way of conveying basic information on a subject and this may account for the presumption that case study is best used as a subsidiary vehicle for the application of knowledge gained from lectures. ${ }^{4}$ However, lectures are less effective than participatory methods for the promotion of thought. Moreover, if it is changing particular attitudes, revealing hidden personal assumptions, values and prejudices that are important (as they must be in any subject that is prescriptive in nature) then lectures are not in the least effective. If 'thinking' is important (and the word crops up fairly uncritically in literature on the teaching of development studies), ${ }^{5}$ then an alternative is required. Generally, participatory methods, such as case study, are suggested as alternatives. 'Making judgements', 'thinking' and 'creative thinking' are valid objectives for a wide range of small group teaching methods. Case study is a participatory method, but it is not the sole participatory method nor is it the only one that involves real world problems.

\footnotetext{
Alternatives small-group methods

Donald A. Bligh [1971: 125-8] lists several university teaching methods together with a statement of the educational transactions which, with proper use,

- Professor Keith Lumsden, Herriot-Watt University is testing case study in economic teaching as part of his work on university level economics teaching.

4 For a detailed consideration of lectures see Bligh [1971].

s See Seers 1967 and also 1979.
} 
they are generally thought to encourage.$^{6}$ An extract from this list, providing information on methods of small groups teaching that we feel might be reason-

\section{teaching method}

Brain-storming: an intensive discussion in which spontaneous suggestions as solutions to a problem are received uncritically

Buzz groups: 2-6 members discuss issues or problems for a short period within a lesson

Case discussion: real or simulated complex problems are analysed in detail for students to suggest their own solutions or decisions

Free group discussion: a learning situation in which the topic and direction are controlled by the student group; the teacher observes

Group tutorial: the topic and general direction is given by the tutor but the organisation, content and direction of the discussion depend on students

Problem centred groups: 4-12 in number, with a specific task to discuss

Seminar group discussion: introduced by the presentation of an essay or other work

Simulation and games: teaching in which a real situation is duplicated in its essential features, perhaps in the form of a game or a problem; participants adopt an appropriate role

Syndicate method: teaching where the class is divided into groups of about 6 members who work at the same or related problems with intermittent tutor contact and write a joint report for the critical appraisal of the whole class

Synectics: development of brain storming in which special techniques, such as choosing group members from diverse backgrounds, are used to produce a creative solution to the problem

${ }^{6}$ In small group work, classroom transactions need to be guided by a well defined, formal understanding of the objectives to be achieved and strategies likely to achieve them. Effectiveness in the use of small group methods can suffer if they are considered to be 'informal' methods, and if, as a result of this, no clear guidelines are established for the teacher and students with respect to their roles in discussion. Formal understanding of the demands of the method and familiarity of usage are both essential for success. able alternatives to case study in some circumstances, is given below.

possible objectives

New ideas, problem solving, decision taking

Training in discussion, group cohesion; consolidation of memory by rehearsal of facts; learning terminology by use; arousal and feedback

Understanding complex inter-relationships; application of principles ${ }^{7}$

Change in attitudes, feelings, human awareness, new ideas

Understanding, thinking at all levels

Evaluation, decision making, analytical thinking and application of principles

Critical thinking, ability to present an argument, thought at all levels

Empathy, self-awareness, attitude change and vocational skill

Skills in seeking and organising information ${ }^{8}$

Creativity, including creative problem solving and decision making

\footnotetext{
7 Note that Bligh's claims for case study are somewhat restricted when compared with claims normally made. The assumption that case study is about application of knowledge gained from elsewhere is maintained.

8 The syndicate method is no stranger to development studies tutors. The IDS makes extensive use of syndicate work on short courses as does the DAG at Birmingham. The Bradford Discussion Case Study seems to be a similar kind of exercise. Bligh's principal objectives for the syndicate method seem somewhat thin. For a discussion of the substantive use of syndicates see E.A.Life 'Henley and the Syndicate Approach', ch 5 in S.Mailick The Making of the Manager, Unitar Anchor Press, 1974.
} 
However, we can look at Bligh's list either as a list of potential competitors to case study, or as providing a range of possible settings in which case study could be used. There is no reason why (say) brain storming techniques could not be used on a very restricted case eg a two paragraph statement on some real world development problem. Looked at in this way, cases could be used to sustain alternative discussions in different contexts. The methods and materials could be matched in an effort to overcome specific problems eg brain storming applied to a short case might have as an objective of the exercise the promotion of divergent thought amongst students inclined to search for the approved answer. If there is no such thing as 'the ideal case method' then it must be possible to slot case material into a number of different educational activities. By so doing a wider range of appropriate skills can be developed.

So far, attention has been confined to alternative ways of promoting thinking activities. The normal argument in favour of case study is that cases unite theoretical knowledge with real world problems and examples. This is undoubtedly an important role for case study, and one that we now wish to examine from the point of view of the student. UK citizens can, and do, study development, but on many UK courses the majority of clients are from overseas. To bring students from (say) Papua New Guinea, Argentina and Uganda to study Third World issues must involve an element of artificiality. Whatever the individual circumstances of students, this kind of study is undoubtedly an activity that is full of stress. Stress might be seen in the types of problems students face in coping with academic discourse itself. Academic communication differs from ordinary communication and certainly differs from the style of interaction individuals (especially those from overseas governments) are used to in everyday life. Teachers discuss issues with each other within a framework of commonly held attitudes and beliefs, particularly a belief in the validity of rational argument, and with a technical and semi-technical vocabulary that is partly of enduring scientific value and partly derived from current fashion. Trying to cope with such conventions (which in effect means giving up normal patterns of communication) is often enough of a struggle for most people, without the added and definite struggle of seeing how a meaningful relationship can exist between the new thoughts and understanding that academic discourse hopes to develop, and concern with the very reality (the developing world) that students have left behind them. Of course many students face this problem whatever and wherever they study, but the gap between discourse and reality is likely to be felt particularly strongly by overseas students, especially when studying through the medium of a second language.

Tim Johns quotes one such student's own analysis of his learning problem:

When I came to Britain I thought it would be easy to do the reading required, since every day in the Ministry at home I have to read and act on numbers of memoranda written in English. However I have found it difficult to get through everything on our reading lists. The problem is I know how memos are written, and what I am supposed to do as a result of reading them; but I don't understand the sort of English used in the books recommended by our lecturers, and I don't know what I am supposed to do with them.

[Johns 1978]

Precisely what such students 'do' with their reading and with other academic tasks set, is a matter that can be investigated empirically. Any desire to promote the kind of thinking currently advocated as essential by development studies teachers must present students of development studies with a chance to grapple with the real world. If a student is struggling with understanding academic talk, rather than with understanding the real world referents of academic talk, he must be under strong pressure to learn the talk, rather than to explore the referents ie the real world of development problems. Whether learning the talk is enough to pass course examinations will depend on the nature of assessment tasks set. Learning the talk can never be evidence of conceptual understanding, not of evidence that 'synthesis' has taken place. ${ }^{9}$

Case study as a small group teaching method may provide precisely the means for studying these referents, and encouraging this very development of understanding, synthesis of ideas, critical ability and so on. ${ }^{10}$ We turn now to some definitions and examples from teaching practice.

\footnotetext{
- The desire to promote conceptual learning is a problem that haunts concerned academics. It is easy to underestimate the educational problem involved in trying to provide opportunities for such learning. An excellent examination of the relationship between concepts, examples and assessment can be found in Markle and Tienann [1970:52-62].
}

10 There are other ways of coping with the problem. Dudley Seers and others have stressed the need to see European problems in the light of development theory [Seers et al 1979]. Seeing patterns of economic activity in the United Kingdom in terms of 'core' and 'periphery' theory for example, opens up the possibility of undertaking a study of problems of marginal areas in Scotland and Wales on a case and field study basis. Field studies can serve very much the same end as classroom case studies, but as with classroom case work, require very detailed consideration at the planning stage if field trips are to offer the possibility of te sting out theories and so on. Field placements are also possible but such work in development studies courses is not likely to 


\section{Examples and Definitions}

\section{The Harvard Case Method}

Historically, the case method of teaching has been very important in disciplines or areas of intellectual speculation where experience rather than some overarching theory has been the main route to understanding real world problems. Thus case study is extensively used in the training of medical students, social workers, business studies and in legal training. It was the Harvard Business School that in the 1920s and $1930 \mathrm{~s}$, pioneered the use of case study in an interdisciplinary context. The power to think creatively and the ability to cope with new problems and experiences were equated at Harvard. Case study was then used as the vehicle whereby students were encouraged to think.

Business studies in the 1920s and 1930s (and many would see a parallel in development studies today) were characterised by:

- a lack of consistent generalisations linked to consistent theoretical framework;

- no clear definition of what constituted business studies;

-a concern to look at business issues in the context of real situations, and hence a concern with practical problems and policy decisions rather than with the development of theoretical abstractions;

-a realisation that the proper scope of the subject was interdisciplinary;

-an acceptance of a student-centred approach, since developing the experience of the individual student in taking responsible decisions was ultimately what counted.

According to Dewing, ${ }^{11}$ thinking is an active process of coping with new problems, and requires therefore not the passive memorisation of lecture material but the active involvement of the student in the thinking process itself. However Dewing accepted that the use of cases meant neither neatness nor completeness: 'as

have the traumatic effect on the learner's perceptions as placement can have for social work students, student teachers or medical students. For a discussion of the advantages and problems associated with placements in local authorities see Nick Devas 'The use of field projects and at tachments in development administration courses', paper presented to the DSA Study Group on the Teaching of Development Studies, Reading, September 1979

1 The reference to Dewing is from the Introduction to Fraser, C.E. (ed), 1931. an ideal of educational method, teaching people to think has none of the conspicuous advantages of teaching accepted truths. As a method it is crude and clumsy in execution. ...' It is also slow and demanding in terms of educational resources (teaching time, classrooms and teaching skills). The early thinkers at Harvard were looking to case study not as a means of applying knowledge gained from lectures but as the way in which concepts and generalisations are developed by the students for themselves. Experience, knowledge and the ability to conceptualise, and hence generalise, is built up bit by bit through the consideration of carefully selected cases [Gragg 1953].

Clearly the Harvard Case Method was relying on some sort of inductive process for the establishing of useful generalisations. In some areas the method was not adequate. For instance, it was recognised that economics and economic problems are not easily dealt with, since economic analysis makes considerable use of concepts and theoretical abstractions (or logical fictions)-economic man, utility, production function, consumer surplus-that are not themselves derivable from cases. (This does not preclude developing principles on a problem-solving basis; it just makes it more difficult. $)^{12}$ In economics, cases tended, therefore, to be means of applying principles.

In short, the following points may be made about the Harvard method:

-cases are reported from life and are real rather than hypothetical. This implies resources going into the identification of appropriate cases (as at Bradford or the Institute of Local Government Studies-see below);

- the problems tackled by case study are real problems calling for action rather than formal academic problems calling for solution. Insight into human behaviour, the ability to identify hidden prejudices and hidden assumptions about people and events, as well as the capacity to see all the relevant facets of a business management problem, are to be developed for the potential manager through the use of cases;

-the method runs into difficulties as a source of appropriate generalisations where induction is not enough to establish useful analytical concepts;

\footnotetext{
12 See Elkan [1975: 212].
} 
-it takes a long time to build up an appropriate sequence of cases and an equally long time for students to adjust to them ie case study is not a quick learning method nor one that is particularly easy to operate successfully;

- the Harvard Method is a postgraduate method and students were expected to apply their own previous training and experiences to problems whenever possible, but it does not assume previous experience in business studies. This raises a methodological question: 'Is case study a means of providing a general orientation or is it a method that depends on a previous orientation? ${ }^{13}$

We move on now to definitions of case study and its role, in contemporary development studies.

\section{Some definitions from the social science literature}

How is case study to be used in the teaching of development studies? In answering questions about educational methods there is of course no general reason for supposing there exists any one conceptual basis on which to establish a correct answer. Nonetheless, it is worthwhile to set out some of the descriptions and definitions of case study that have been provided in areas of teaching relevant to development studies.

\section{Sandford and Banbury offer the following:}

A case in economics may be defined as the consideration of an actual or closely simulated economic event, situation, development or policy measure. A case is characterised by being detailed, limited and unified. These features are complementary and the terms are relative: the detail is more than that which would normally be included in a general textbook or course of lectures appropriate to a particular educational level: the limitation of scope is partly a consequence of the detail necessary to ensure that the case effectively makes a point, and the unity arises from confining attention to a subject matter which is circumscribed and which usually has a clearly marked beginning and end. In other words, a case is generally specific to a place, a theme and a time. [Sandford and Bradbury 1975: 243]

Sandford and Bradbury distinguish between cases designed to illustrate principles, and cases designed to be a means whereby principles are derived. They point out that cases need not be restricted to written

\footnotetext{
${ }^{13}$ Fuller [1975] says, in contrast, 'The value of case-studies in the training of experienced personnel is stressed because the effectiveness of this method depends to some extent on the amount of relevant experience which students can bring to the exercise and on which they can draw'. For a consideration of this and other methodological points see Meno Lovenstein [1960: 138-62].
}

material: film, video-tape or taped material can also be used. They accept closely simulated events as suitable. ${ }^{14}$ The objective of using case study, as they see it, is to introduce realism and to involve students in specifying relationships, isolating concepts, evaluating data, making predictions and taking decisions.

Lawrence, who assisted in the development of the Harvard Method, describes case study in terms that many development studies teachers might find appealing:

The vehicle by which a chunk of reality is brought into the classroom to be worked over by a class and an instructor. A good case keeps the class discussion grounded upon some of the stubborn facts that must be faced up to in real life situations.

[Lawrence 1953: 215]

D. J. Murray [1974] discussing case study as used on course in public administration, classifies case study as follows:

a) short, invented and cumulative cases on a particular problem which is then to be solved by the reader or group;

b) similar studies to the above but based on actual episodes;

c) a narrative account of some particular administrative behaviour as a case in which a course of events is followed through to some suitable terminal point such as a decision. The case is then used as a practical example for discussion;

d) an extended research enquiry which is presented as a case because of the way in which the researcher conceives the whole process of social science research.

\section{Examples from courses}

At the Project Planning Centre at Bradford, case study is defined as 'a teaching instrument that is based on a real situation in the practical world of operation. In the projects context, this would imply that the teaching instrument was based on an actual project plan, or on a project that had been undertaken and implemented' [MacArthur 1978].

Four types of cases are used at the Centre, namely:

a) the narrated experiences of individual tutors;

b) case studies that illustrate methods of project analysis;

14 Parish [1977] in looking at teaching methods in development studies courses distinguishes simulations from case studies but does not provide us with any justification for doing so. 
c) case studies as a basis for exercises in the techniques of project analysis;

d) case studies used for discussion seminars where each participant must present a critique of a project report to a group of his colleagues [Potts 1978].

Case studies used at the Department of Administrative Studies in the University of Manchester are very much studies of particular real world examples drawn from specific countries. They aim to create in the classroom 'real work situations' for study by more or less experienced administrators. Since groups are drawn from a number of countries, cases are expected to form the basis for teasing out common problems through group discussion as well as to provide the raw material for policy development in the particular area that the case deals with. Cases are expected to be both relevant to students from a number of countries, and detailed. The justification for the use of case studies is therefore partly educational (in that students are experienced, primarily task-orientated and from similar work backgrounds though from different countries) and partly from a reflection of underlying academic values that sees cases and the study of cases as a means of furthering understanding of real world development issues. ${ }^{15}$

This use of academic material is not always followed elsewhere. At the ILGS, cases are specifically researched and written up as teaching material rather than as academic research topics. (This is not to deny that they have academic validity: it is a question of emphasis. $)^{16}$ One advantage of specially prepared material is that it can be accurately matched to the needs of particular courses and students. Whether such a matching of 'needs' is possible in an academic as opposed to a training context is itself a subject for investigation.

\section{Common Elements}

In all the above there is, of course, no single definition of what constitutes a case. Whitaker [1960] goes

\footnotetext{
1. At the Institute of Development Studies, at the University of Sussex, case studies on the MPhil course tend to be. in effect, the study of cases. finding justification not within an educational argument based on learning by doing or activation of previous knowledge, but on some scientific argument that seeks out a generalisation or question and tests this question against the experiences of particular countries called 'cases'. The cases consist not of one document prepared for educational purposes but a series of books, research articles. monographs that outline the experience of particular countries. Students attend lectures and tutorials but are not expected to manipulate the material to achieve any particular kinds of outcome.

16 Several cases are available eg David Pasteur "The Metroville water supply exercise', Case Studies in Development Administra tion, DAG, ILGS, 1976. C. J. Davies Problems in urban management, Case Studies in Development Administration, DAG, ILGS, 1976.
}

further than this to argue that the re is no such thing as 'the case method'. Cases, he argues, come in a variety of forms and can be used in a number of different ways. And this is indeed borne out by the list of alternative, but not mutually exclusive, teaching methods outlined above. Some sort of case study has a role to play as a teaching and research device in a whole range of different subjects and educational contexts, and no single common set of attributes will be found in the multitude of materials and situations in which case study is used. Although no single definition is fully adequate, this is not argument for refusing to isolate the various dimensions of case study. The Sandford and Bradbury definition, which seems to be the most comprehensive, suggests reality and realism (or concreteness, since they include invented data), direct student involvement in some sort of manipulative relationship with the material, and an awareness of the distinction between inductive and deductive processes. Realism, group work, application and interaction among students and between students and materials are suggested in the other definitions and examples provided. The best we can offer is a non-specific definition: case study is the name applied to any teaching method that, on the basis of some detailed or stylised representation of reality, invites students to take (or advocate) decisions singly or in groups. As a rider, we might add that the creation of such material relating to the real world suggests a research capability of some sort.

If a case study is correctly seen as the use of problem-centred material to sustain participatory methods of teaching, particularly in small groups, then relevant practical issues for discussion are:

-the collection and editing of appropriate cases;

-the role and expectations of the tutor;

-the expectations of the students and the actual (as opposed to the planned) activities in which they become involved through use of the case study material;

-the amount of case material used;

—evaluation/assessment procedures.

\section{The Practicalities of Case Study}

\section{Selection of cases}

There is relatively little publicly available material on the criteria for the selection and development of cases for use in development studies teaching, nor on the particular objectives the cases are trying to 
achieve, or educational success in achieving stated objectives. Fuller, for example, is sceptical of the usefulness of those cases that describe 'the inputs' to a particular programme but which fail to provide information on the outcome [1975: 150-1].

Fuller uses a wide selection of documents in the study of the SRDP. On the other hand, many busy teachers complain that such an approach to case study work makes the use of cases unmanageable when its use must be accommodated within a wider course structure. There is an argument to be made for short snappy case material as well as for extensive cases. Data response questions, currently finding favour with economics teachers as assessment instruments in unseen examinations, are, in effect, short cases. There is no reason in principle for cases being either lengthy or short. It all depends on the final objectives.

One other advantage of case study in preparation of case material is that it is a useful way of generating not only material to be used in particular sessions, but literature for the course as a whole.

Milward and Kennedy [1974] correctly point out that suitable reading material for interdisciplinary courses is difficult to find, since subject-based literature uses subject-specific concepts, language and frames of reference. No doubt this problem is slowly being overcome in development studies through the publication of broader based material. If normal academic material is used as a source both of case study and general reading material on an interdisciplinary course, it needs careful selection.

The conflict between the need to select and edit cases and the desire to capture the complexity and total reality of a problem is one that is felt keenly by some case writers, especially if the cases are to be used as the main way to achieve integration. Gavin Kitching, in trying to illustrate the mixture of untidy activities that make up 'development planning', feels that a standard 'academic' approach based on reading of books and articles about planning over-refines concepts such as 'definition of objectives', 'data collection' and, as such, distorts understanding. At the same time, Kitching recognises that a case is itself an abstraction. Even where the subject matter is excellent for interdisciplinary study ('planning') tradeoffs are unavoidable, viz:

Case study in all its variants is a mechanism for attempting to capture the complexity and total reality (comprehensivity) of a given object of study (particularly where part of the object involves human activity and interaction). The snag is, how- ever, that complexity and comprehensivity are not quite the same thing. . . . This of course implies that case study construction, as much as the writing of a lecture or handout, is an exercise in abstraction. ... [personal communication October 1979]

Case study, as interdisciplinary reading material, like case study as a teaching method, can support a number of objectives but not always at the same time. Furthermore, it cannot be assumed that the study of one particular case is adequate to test student understanding of specific concepts. Cases either need to be cumulative, or to be specially constructed to test for both over- and undergeneralisation (see below).

\section{Role of the tutor}

Useful discussion of the tutor's role can be found in the Bradford paper referred to earlier. An exhaustive and helpful account of the alternatives open to tutors working with small group methods of teaching can be found in the work of Jean Rudduck [1978]. Case study methods are not teacher nor student proof. For effective implementation the tutor needs to analyse carefully the objectives that the material is supposed to make possible. He needs to think of formal procedures for achieving such objectives and to be clear about his own role and the role that is expected of students. Cases and other small group methods have too often been described as informal methods of teaching. Careful analysis of alternative usage suggests that for success, there needs to be a high level of formal understanding of the expected procedures. In addition, the teacher needs to specify educational tasks and objectives and to set out work patterns that will achieve them. Patience and tolerance will be required on his part as students learn to adjust to the roles that active involvement with case material requires.

Students in general tend to be conservative in their tastes for educational methods, especially if they come from education systems that rely very much on lecturing and passivity. If a smooth transition is to take place to case work methods, some clarification of student roles and tasks is essential.

\section{Assessment and evaluation}

Students we assess, materials we evaluate. The evaluation of the effectiveness of case study as an educational method tends to be either impressionistic or restricted to the administration of a questionnaire after the completion of the study. Fuller, in looking at student appreciation of case study material, collected post-course data on relevance of subject matter, appropriateness of presentation and student understanding. Subjective evaluation on a 
four point scale was the method chosen. Any evaluation is better than none and, given students from many countries, and the extensive study of a case from one particular country, relevance is undoubtedly an issue of import. However post-course evaluation of this sort is, in the event of a hostile response, too late.

Strong claims have been made for case study, and it seems to us that it is time that some of these claims were put to the test empirically. The evaluation of the effectiveness of case material is crucial where resources are being devoted to the construction of such material for specific educational purposes. It should certainly be possible to specify the objectives that use of a particular case is likely to support (indeed the case researcher must have some objectives in mind before he starts collecting material) and to test for realisation of objectives against actual outcomes. Conventional educational evaluation requires some kind of control. The trouble with such evaluation is that it is time consuming, and may not be particularly relevant. Illuminative evalation [Parlett and Hamilton 1977], concerned more with an understanding of the educational transactions that actually take place when case study is used and with how student, and teacher, perceptions have changed over time, seems a more appropriate way to think about the evaluation of case study work. Such an evaluation requires the continuous observation, by an outside observer, of the actual transactions that take place during a case study session, as well as exploration of student and teacher views before, during and after the series of case sessions that make up part of a course. We have seen no such evaluation of the use of case study in development studies teaching, and suggest that such an evaluation is required in order to put the claims made for case study into some perspective.

Case studies have been suggested as a suitable tool both for the development of conceptual thinking and as a means of assessing whether or not students are thinking conceptually. There is no reason for assuming that case material will achieve this without very great care being given to the construction and sequencing of the material. To see what is implied by conceptual thinking we need to spend a little time looking at concepts. Suppose we have to instruct students in the use of some technical concept $\mathbf{A B C}$ and that in a lecture we outline the defining characteristics of the concept $\mathbf{A B C}$ and provide a real world example ABCW. We cannot be certain that the student has understood that the defining characteristics of the concept are $\mathbf{A B C}$ until he has been asked to recognise other examples and nonexamples of the concept. Cases can be used to test understanding: thus students can be provided with a number of real world examples ABCX, ZABC, $Y A B C$ and $A B X Z$ embodied in a case. If students have understood the defining characteristic of the concepts they will be able to organise the examples on the following basis and thus avoid both overgeneralisation (seeing $\mathrm{ABXZ}$ as a valid example of the concept) and undergeneralisation (not seeing YABC as a valid example of the concept) ${ }^{17}$ In other words, case study as a means of either developing analytical thinking, or of assessing for analytical thinking, will need very careful construction. It is the ability to recognise instances and noninstances of analytical concepts, disguised by contingent real world conditions, that enables professionals to interact successfully with the real world, rather than their ability to relate one case study to another. Practice in recognising instances would seem to demand the use of more than one case study.

Actual development studies problems are likely to be linked one with another not in terms of a common set of defining characteristics but rather in terms of family likenesses one with another. Suppose we have a topic 'development policy in socialist economics'. If we searched amongst socialist countries for a common set of defining characteristics, we might not come up with a set of characteristics that are stable. However we might feel that economies such as Cuba, Tanzania, Yugoslavia and China share a certain family resemblance ${ }^{18}$ that enables us to use the term 'socialist economy' to cover all the instances given. Many areas of development studies work are linked in this way. The problem for both the expert and the student is to recognise resemblances amongst cases that become suggestive of the types of question that require asking, and the kinds of extended concepts that become appropriate. As with real life experiences of this nature, case study to achieve this end again needs to be cumulative.

${ }^{17}$ If readers are confused let them take a technical concept eg money and then specify the defining characteristics of money (paper or metal are not defining characteristics but an $X$ or a $Y$ in terms of the above example) and then test the example against particular instances of money. Extend the instances to cover various definitions of the money supply and see if the defining characteristics are constant. If not, then we are not dealing with a technical concept but an extended concept.

${ }^{18}$ Wittgenstein [1958] explores family likeness and compares it to the overlapping fibres that make up a rope: there is no fibre coextensive with the rope. An excellent account of problems involved in identifying, applying, modifying and extending concepts is to be found in Sawers [1967: 167-73]. We feel that many students experience great difficulties in understanding the source and purpose of concepts, the range of concept types and how they match up with reality. We take success in application to signify understanding of concepts but this need not necessarily be true. It depends very much on a) whether under- and- overgeneralisation has been tested for, b) whether the example on which application is practised is new. 


\section{Case Study as a Form of Research Activity}

The use of case study has been talking point in development studies ever since the publication of 'The economics of the special case'. Seers [1962] applied his argument against the over-use of conventional Keynesian theory on all fronts, ranging from the construction of curricula, teaching methods and textbook writing, to basic methodological issues such as the validity of generalisations drawn from the particular experiences of industrialised countries. Case study and typology were put forward as possible starting points in the search for more appropriate generalisations in the development studies field. Seers was particularly concerned with cases as research instruments rather than as material to be used to support a given form of teaching. He himself has continued to explore issues of typology, making progress with respect to questions of relevance to developing petroleum-exporting economies but, on the whole, proceeding rather slowly with a typological schemata for the classification of cases. Curiously enough, his paper gave impetus to the development and use of cases for teaching purposes but, whereas Seers himself was particularly concerned with macro-issues, our impression is that cases actually developed and used on development studies courses as specially designed teaching instruments tend to be micro rather macro in orientation. ${ }^{19}$

Research aimed at the preparation of teaching material on a case basis has already been discussed. Here the concern is with the use of case study (be it description, narrative or any other form) as a research tool. Cases as research devices raise certain issues of methodological import for the growth of development studies as a distinct discipline. Is the aim of the study to establish higher level theories of development or is it to establish a framework of ideas suggestive of how certain types of real world problems are to be handled? No doubt practitioners can place themselves on a spectrum that runs from the purely theoretical to the purely pragmatic. There are over this spectrum a number of arguments favouring the use of case studies.

19 There are notable exceptions to this, eg Gavin Kitching's planning simulation Ruritania as used at the University of Swansea. Our impressions may be wrong since many specially prepared cases remain anonymous. Henderson's bibliography on manipulative cases (attached in Appendix $I$ to this article) is an attempt to bring such cases to wider notice. This tendency to micro rather than macro is noted in economics literature and the pattern is sometimes explained by macro-economic theory being 'less specific in either temporal or spatial dimension' as cases are supposed to be limited 'to a place, a theme and a time'. See Maunder [1977: 49-55]. This is not an explanation that we are inclined to accept.
Undertaking research on a case basis can be a way of building up the number of instances over which a well established generalisation is held to be appropriate eg further cases indicating that rural producers evaluate risks and seek some long-term survival solution to their production problems. This process of filling out is part of the normal routine activity of science. Another use of case work might be to test some established theory, an activity that is only slightly different from the first mentioned. A further use of research work undertaken on a case basis is not to test models and theories but to suggest the need for generalisations. This is the role that case studies and typologies have in the Seersian approach. An accumulation of comparative cases might provide the means for constructing new theories. Seers has laid emphasis on systematic and comparative research specifically concerned with changes in economic structure as development proceeds. Comparisons of development experience on a case basis (eg industrialisation and trade policies in a number of countries) and multinational research projects area now fairly well established features of the development scene.

Case study can be used not to further the development of higher level theory but to remind us that the real world is a highly complex place. As D. J. Murray puts it:

Case studies add something totally different to the fund of human knowledge. They show something of the great variation in circumstances and their manifold complexities. They show how those variables handled in abstract models and theories are in practice embedded in human situations. . . .

[Murray 1974: 167] ${ }^{20}$

Pragmatists will accept this argument, theorists will see it as the very reason why abstractions and generalisations are essential.

Academic subjects are normally expected to develop a unique view of the world, a method for the identification and handling of a problem and a technical and semi-technical vocabulary for the analysis of that problem. Teaching a subject normally involves recreating learning situations within which activities are paralleled in classroom work. Thus if the comparative method is important for the development of ideas in the subject, then in the teaching and learning activities, comparisons must be made. Similarly if the study of cases is important to the way in which a

20 Murray similarly discusses cases as research devices in administ- 
subject builds up knowledge, then case study must have a significant role to play in teaching. Clarification of methodological issues ought to create a situation in which curriculum and teaching questions are easier to solve. However reference to subject needs alone will not be enough when teaching takes place both on an interdisciplinary ${ }^{21}$ and transcultural basis.

\section{Conclusion}

Various dimensions of case study have been explored in this paper, in an effort to clarify some issues relevant to the use of case study as a teaching device in development studies. Cases as a research tool as well as teaching material have been looked at, together with arguments for the sustained use of cases in interdisciplinary studies. In general, we feel that cases are basic to the way in which development studies itself furthers its theoretical understanding of the world, and we are prepared to recommend their use on this basis. At the same time we wish to stress that theoretical abstractions are often essential to illuminating issues, and these cannot always be derived successfully from the study of cases. Indeed, many theoretical abstractions are fictions, and cannot therefore be directly derived from factual knowledge or observation.

A great deal of attention has been focused on sorting out the various educational objectives that the use of case study might further, particularly when used as a small group teaching method. It was felt that the 'one off' use of case material was unlikely to meet the various objectives, and that the cumulative use of cases could only be guaranteed to do so when the cases tested not only for 'application' but for over- and under-generalisation. Furthermore, for the achievement of objectives relating to the development of analytical thought or imaginative thought, a variety of alternative small group methods might also be useful, especially where short cases were involved. The appropriate selection of particular methods once again calls for a more selfconscious analysis of individual learning problems and objectives. The whole issue of cases as a way of promoting critical thought in development studies has, we feel, an empirical dimension. It is possible to identify criteria for the identification of 'critical thought' and to investigate the educational transactions sustained by case study while they are being actually used, in order to see whether 'thinking' is being promoted. Such work would demand clearer

21 Other details of course organisation on an interdisciplinary basis will not be solved in this way. Interdepartmental negotiation, even interpersonal negotiation and a strong commitment to the idea of development studies will be required to sustain a course. For a discussion of implementation problems see Barnett and Belshaw [1975]. articulation of students' learning problems, teaching objectives, and analysis of skills being tested for in assessment instruments, as compared to what is treated in actual classroom work. Some sort of illuminative evaluation of the use of case study might be a starting point. Indeed such an evaluation is particularly important where resources are being devoted to the development of specially selected cases. Proper educational analysis in the use of such cases is a before, during and after exercise.

With respect to the relationship between courses and case material, or between the use of lectures and cases, we hold that there is no ideal relationship that can be established $a$ priori. The relationship very much depends on what the course (or course teachers) are trying to achieve, the learning problems of the particular group for whom the course has been developed, and the amount of educational resources and the degree of institutional freedom available to course planners. The main advantage of case study material is that it encourages students to interact with the real world on the same basis as a development studies expert, and attempts to recreate the stimuli that such an expert notices and reacts to in field conditions. The development and application of concepts and the sequence 'problem . . . concept development $\ldots$ application ... appropriate generalisation ... modification or extension to similar problems' . . . is circular. Given this, case study can be used at any stage in the process and not simply to apply knowledge gained from lectures. From what is known about over- and undergeneralisation, we feel that the use of cases perhaps needs to be cumulative, wherever it is used in the sequence.

Case material can be used as a means of assessing students. This can be done on a subjective basis by evaluating contributions to discussion during teaching sessions that make use of case method. Case material can be introduced into unseen examinations either in modified form (data-response questions) or as mini-cases. If the objective is to test for application of technical concepts, the example given should not be one already used in class.

Our general conclusion is that more attention needs to be given to the self-conscious analysis of educational issues, especially where cases are being used to integrate ideas not only amongst disciplines but across cultures. Clearing up methodological issues (such as the relevance of theory received from existing disciplines, and the role of the study of cases where no single overarching theory is thought to be strictly appropriate) is likely to be important in clarifying educational issues, but may not be enough 
in itself. Problems experienced on a particular course or particular types of courses are capable of empirical investigation. The Teaching Development Studies Group organised by the Development Studies Association might be an important channel for the stimulation of educational discussion for specific educational purposes. Perhaps the Development Studies Association could not only help establish priorities for educational research in the teaching of development studies but could also establish some kind of case clearing house for the documentation and exchange of case study and other teaching material relevant to the teaching of the subject at university level.

\section{References to works not included in bibliography in Appendix I}

Barnett, A. S. and D. G. R. Belshaw, 1975, 'Rural development: an approach to interdisciplinary teaching', in 'Integrated Social Sciences', Case Studies in Interdisciplinarity, no 3, The Nuffield Foundation Group for Research and Innovation in Higher Education

Bligh, Donald A., 1971, What's the Use of Lectures?, London University Teaching Methods Unit

Elkan, Walter, 1975, 'How one might teach economics to undergraduates', Economics, vol 11 part 4, Winter

Fraser, C. E. (ed), 1931, The Case Method of Instruction, Harvard

Fuller, Colin, 1975, 'The special rural development programme in Kenya: its use as a case study in the Department of Administrative Studies in the University of Manchester', Journal of Administration Overseas, vol 14 no 3, July

Gragg, C. I., 1953, 'Because wisdom can't be told', in K. R. Andrews (see bibliography)

Johns, Tim F., 1978, 'The text and its message: an approach to the teaching of reading strategies for students of development administration', University of Birmingham

Lawrence, P. R., 1953, 'The preparation of case material', in K. R. Andrews (see bibliography)
MacArthur, J. D., 1978, 'The use of case studies in the Project Planning Centre for Developing Countries', Bradford, mimeo

Markle, S. M. and P. Tienann, 1970, 'Problems of conceptual learning', British Journal of Education Technology, vol 1 no 1

Milward, A. S. and G. Studdart-Kennedy, 1974, 'Crossing subject boundaries', Times Higher Education Supplement, 5 vii

Parlett, M. and D. Hamilton, 1977, 'Evaluation as illumination', in Parlett and Dearden (eds), Introduction to Illuminative Evaluation, Pacific Soundings Press, Berkeley

Potts, D., 1975, 'The use of seminar discussion type case studies at the Project Planning Centre', Bradford, mimeo

Rudduck, Jean, 1978, Learning through Small Group Discussion, Society for Research into Higher Education, Guilford

Sawers, R., 1967, 'The application of a concept', ALTA: The University of Birmingham Review, no 3 , Summer

Seers, Dudley, 1967, 'The economics of the special case', in Martin, Kurt and John Knapp (eds), The Teaching of Development Economics, Frank Cass -1979, 'The birth, life and death of development economics: revisiting a Manchester conference', in a special issue in honour of Kurt Martin, Development and Change, vol 10, pp 707-19

-, B. Schaffer and M. Kiljunen (eds), 1979, Underdeveloped Europe, IDS and Harvester Press

\section{Appendix I}

Case study as a teaching/learning method in development studies: a select bibliography

The idea of a bibliography on Case Study as a Teaching Method in Development Studies arose out of a two day Teaching Methods Workshop held at the Project Planning Centre, University of Bradford, on 4-5 January, 1979. The bibliography was proposed in response to some of the questions that troubled the Bradford meeting. Specifically these were questions of scope, definition, length, pedagogic procedures, management and the amenability of case study to different kinds of tasks. The bibliography could not, in the time and with the 
resources available, pretend to be comprehensive. It aims to do two things:

a) to serve as an introduction to both educational and discipline-related literature on case study as a method of teaching/learning;

b) to provide a sampling of some of the manipulative case studies used on development oriented courses in UK universities and other higher level institutions.

The bibliography is therefore divided into two sections. Part one provides references to literature primarily of an educational type but largely within disciplines relevant to development studies. Section two focuses on coherent case studies developed for use on specific development studies courses. The latter was more difficult to compile since the material referred to could only be tracked down via individual contacts with appropriate departments in various universities. Some subjects (politics, sociology) are under-represented: partly through bias in collecting and partly because case study in these disciplines often means the study of some continuous narrative rather than an 'action' oriented/decision oriented simulation or discussion. 1 t is not a trivial question to ask why the pattern of entries are what they are.

The guiding principle for the inclusion of a reference was a positive answer to the question "ls this reference likely to be useful to those teachers of development studies approaching case study for the first time?'

There are other bibliographies on case study and related teaching devices. Such as are relevant are mentioned in the text. References in Maunder [1977] are useful. References to commercially available cases and simulations can be found in Taylor and Walford [1974].

I hope that this bibliography, however incomplete, will prove to be of some assistance to those interested in the production and use of case study material for the teaching of development studies. Contacts for material referred to in Part 2 were made through the Bradford meeting, through CONTACT (the Exeter University Teaching Methods Programme) and, of course, among the wider membership of the Development Studies Association. This opportunity is taken to thank all of these individuals and institutions who have assisted in the compilation of the lists. Anyone who feels that they also have case studies likely to be of interest to a wider audience should contact the author (Willie Henderson).
Bibliography: case study and the teaching of development studies

Part 1: Case Study as a Teaching/Learning Method

Armstrong, R. H. R. and J. R. Taylor (eds), 'Instructional Simulation Systems in Higher Education', Monographs in Teaching Methods no 2, Cambridge University Press

Andrews, K. R., Case Method of Teaching Human Relations and Administration, Howard University Press, 1953

Abercrombie, M. L. J., Aims and Techniques of Group Teaching, Society for Research into Higher Education, London

Brace, Diane, 'The use of simulations, role-playing and gaming to achieve learning', Teaching Politics, vol 2 no 1,1973 , pp 23-7

Burch, Martin, 'The use of primary sources as aids to teaching and learning', Teaching Politics, vol 7 no 2, May 1978

Chambers, R. J. H., 'The use of case studies in public administration training in Kenya', Journal of Administration Overseas, vol 3 no 3, 1964

Charan, Ram, 'Classroom techniques in teaching by the case method', Resource: The Bulletin of the Case Clearing House of Great Britain and Ireland, Issues 8 and 9, 1978

Cockburn, Barbara and Alec Ross, 'Participatory Discussion', Teaching in Higher Education Series: 4, School of Education, University of Lancaster

Davies, C. J., 'The case method in the study of development administration', Journal of Administration Overseas, vol 15 no 4, October 1976, pp 229-34

Ellis, K. 'An empirical approach to management training' (with short case), International Cooperative Training Centre, Loughborough, 1978 , mimeo

Eraut, M., N. Mackenzie and I. Papps, 'The mythology of educational development: reflections on a three-year study of economics teaching', British Journal of Educational Technology, vol 6 no 3, 1975, pp 20-34

Fels, R. and R. G. Uhler (eds), Casebook of Economic Problems and Policies: Practice in Thinking, St. Paul, 1973 
Felton, Jr, Edward L., 'Teaching by the Case Method and Checklist for Effective Case Method Teaching', Course Note Series CN-531, Training Materials, Economic Development Institute, November 1979

Fraser, C. E., The Case Method of Instruction, McGraw-Hill, 1931

Fuchs, U. R. and A. W. Warner, "The "casemethod" approach to teaching elementary economics' in Knopf and Strauss, The Teaching of Elementary Economics, op cit, chapter 1, pp 8-23

Golembiewski, R. and M. White, Cases in Public Management, Rand McNally, 1973 (interesting commentary on method)

Isaac, J. F. 'Using case studies as a teaching approach', Journal of In-Service Education, vol 2 no 1,1975 , pp 22-5

Knopf, K. A. and J. H. Stauss (eds), The Teaching of Elementary Economics, Holt Rinehart, New York, 1960

Leftwich, Adrian, 'The role of case-studies in training work: principles, problems and possibilities', Agricultural Training Board Tutors' Workshop, Agricultural Extension and Rural Development Centre, Reading, July, 1979

Lesser, Barry, 'A comment on the case study approach to teaching economics', Economics: The Journal of the Economics Association, vol 14 part 1 no 61, Spring 1978, pp 9-10

Lovenstein, Meno, 'Economics, educational philosophy and psychology', in Knopf and Stauss, The Teaching of Elementary Economics, op cit, pp 138-62

Maunder, Peter, 'The case study approach in bridging actuality with theory', Economics: The Journal of the Economics Association, vol 13 part 2 no 58 , Summer 1977, pp 49-55

Megarry, J. (ed), Aspects of Simulation and Gaming, Kegan Paul, London, 1977

Murray, D. J., 'Case studies as a form of enquiry', Social Sciences: A Third Level Course Public Administration block 2 part 4, Open University, pp 163-72

McNair, Malcolm P. (ed), The Case Method at the Harvard Business School, McGraw-Hill, 1954
MacArthur, J. D., D. J. Potts and Wilson, 'Experiences in the use of case studies for teaching project analysis', Project Planning Centre for Developing Countries, Bradford, 1979, mimeo

Novogrod, R. J. et al, Case Book in Public Administration, Holt Rinehart, 1969

Nuffield Foundation, Small Group Teaching: Selected Papers, A Report by the Group for Research and Innovation in Higher Education, 1976

Parish, Caroll M., Teaching and Learning Methods and Materials in Selected University Courses for Overseas Students, University of Reading Agricultural Extension and Rural Development Centre, June 1977

Ray, G., 'The use of case studies in the integration of research and teaching in management education', Management Decision, vol 14 no 1, 1976

Rudduck, Jean, 'Small group learning and teaching', in Small Group Teaching, op cit, 1976, pp 3-15 related

Sandford, C. T., and M. S. Bradbury, Case Studies in Economics: Projects and Role Playing in the Teaching of Economics, Macmillan, London 1971

Sandford, C. T., and M. S. Bradbury, 'The use of case studies in economics', in Norman Lee (ed), Teaching Economics (2nd edition), chapter 18, Heinemann Educational Books, London 1975, pp 243-53

Stein, H., Public Administration and Policy Development, Inter-University Case Programme/Harcourt Brace, 1952 (interesting commentaries on method)

Taylor, J. L., 'Social science instruction simulation systems: a selected bibliography', Project Paper no 4, Research Institute for Social Science, Sheffield University, 1969

Taylor, John and Rex Walford, Learning and the Simulation Game, The Open University Press, Milton Keynes, 1974

Taylor, John L., 'Learning to Learn-An Anthropological Approach to Simulation Evaluation', Proceedings of the 6th Annual ISAQA Conference, Polytechnic University, Milan, 1976 
Taylor, John, 'Development control case studies in the training of planners' in Development Control, A. G. Simms (ed), PTRC Education and Research Services Ltd, 1977

The Case Clearing House, The Case Clearing House Bibliography of Selected Cases, Cranfield Institute of Technology, Spring 1974 (with annual supplements)

Tedesco, P., 'Using case studies to teach economics', Rapport no 5, Winter 1976

Warner, A. W. and V. R. Fuchs, Concepts and Cases in Economic Analysis, Harcourt Brace, New York, 1958

Whitaker, F. P. G., 'The use of cases in a university', Case Study Practice, British Institute of Management, Bedford, 1960

Part 2: Case Study Produced Specifically for Development Studies

Armstrong, R., C. Davies, M. Doyle, and A. Powell, Case Studies in Community Work, vol 1, Department of Adult and Higher Education, University of Manchester, 1974

Armstrong, R., C. Davies, and M. Doyle, Case Studies in Overseas Community Development, Department of Adult and Higher Education, University of Manchester, 1975

Austen, A., 'The Asiatic Plough and Agricultural Machinery Co Ltd', Business management case study involving use of case documents, Department of Management Studies, University of Leeds, 1978, mimeo

Agricultural Extension and Rural Development Centre, TIGRAI: Preparation of a Regional Development Plan, University of Reading, 1978

Agricultural Extension and Rural Development Centre, FEDBAC: Exercise on Indicative Planning at Regional and National Level, University of Reading, 1976

Copley, J. H., 'Simulation exercise on the Middle East', Teaching Politics, vol 6, 1977, pp 41-9

Davies, C. J., Urban Services, vol 4, Case Studies in Development Administration, Development Administration Group, Institute of Local Government Studies, University of Birmingham, 1976
Davies, C. J., Problems in Urban Management, Case Studies in Development Administration, vol 3, Development Administration Group, Institute of Local Government Studies, University of Birmingham, 1976

Davey, Ken, KILIMO: A Rural Development Planning Case Study, Institute of Local Government Studies, Overseas Development group, 1978

Department of Administrative Studies, University of Manchester, 'Case Study on Decentralisation: Government of Bhagaria', Methodology of Public Administration Training Course

Department of Administrative Studies, 'Case study on Ahero land development scheme: some lessons of experience', M. J. Boodhoo and C. Fuller, Research Series no 2

Department of Administrative Studies, 'A Case Study in Development Strategy in an ExportDependent Economy: Panama, 1974: Student Evaluation of Policy Options', Department of Administrative Studies, University of Manchester, May 1978

Department of Administrative Studies, Colin Fuller, 'The Special Rural Development Programme in Kenya: its use as a case-study in the Department of Administrative Studies in the University of Manchester, Journal of Administration Overseas, vol 14 no 3 , July 1975

Department of Administrative Studies, J. R. Nellis, 'Prelude to Arusha: a study of productivity problems as a rural development scheme in Tanzania', Journal of Administration Overseas, used with supplementary material as Case Study on Department of Administrative Studies Methodology Course, Manchester 1974

Ellis, K., 'Planning economic appreciation of Umoja village' (basis for study of successive steps in cooperative development), International Cooperative Training Centre, Cooperative College, Loughborough, mimeo

Institute of Education, University of London, The Republic of Mortadella and its Curriculum (educational planning and curriculum development), 1977

Kitching, Gavin, 'Simulation exercises for the teaching of planning: the example of Ruritania', IDS Bulletin, vol 9 no 3, pp 53-9, February 1978 
Kitching, Gavin, 'The Planning Process: Ruritania', Centre for Development Studies, University of Swansea, MSc course in Social Planning, 1978

Leftwich, Adrian, 'The Problem of Pitsilia: a Case Study', Agricultural Extension and Rural Development Centre, University of Reading, 1979

Mayo-Smith, Ian, Case Studies and Notes for Case Leaders, Kenya Institute of Administration, Government Printers, Nairobi

Papanek, G. F., D. M. Schydlowsky and J. J. Stern, Decision Making for Economic Development: Text and Cases, Boston, 1971

Pasteur, D., 'The Metroville Water Supply Exercise: a Case Study in Project Appraisal and Implementation in a Large Scale Infrastructure Project', Case Studies in Development Administration, vol 1, Development Administration Group, Institute of Local Government Studies, University of Birmingham, 1976

Pasteur, D., 'Financial Resources for Urban Services and Development in Lusaka: A Case Study and an Exercise', Occasional Papers in Development Administration, no 3, Development Administration Group, Institute of Local Government Studies, University of Birmingham, 1978
Roemer, M. and J. Stern, The Appraisal of Development Projects: A Practical Guide to Project Analysis with Case Studies and Solutions, Praeger, 1975

Roy, R. S., EDMANEC: Education, Manpower and Economic Planning Simulation Exercise, International Institute for Labour Studies, Geneva, 1971

United Nations Department of Economic and Social Affairs, A Manual and Resource Book for Popular Participation Training, vol 1: Introduction, UN, New York, 1978 (Order Number ST/ESA/66)

United Nations Department of Economic and Social Affairs, A Manual and Resource Book for Popular Participation Training, vol 2: Selected examples of innovative training activities, UN, New York, 1978

United Nations Department of Economic and Social Affairs, A Manual and Resource Book for Popular Participation Training, vol 3: A selected group of training approaches, UN, New York, 1978

United Nations Department of Economic and Social Affairs, A Manual and Resource Book for Popular Participation Training, vol 4: Techniques, UN, New York. 1978 